\title{
The Effects of Perceived Organizational Support and Job Efficacy on Social Workers' Job Performance
}

\author{
So-Yun Choi 1 )
}

\begin{abstract}
The purpose of this study was to investigate the effects of social workers' perceived organizational support and job efficacy on their job performance. A hierarchical regression analysis was conducted to control the influence of social workers' personal characteristics on job performance and to identify the impact of organizational support. Model 1 included gender, and one of different variables was added to the specified Models. Employment type (regular/irregular worker) was added to Model 2, job efficacy to Model 3; and organizational support to Model 4. Model 1 had no statistical significance and Models 2, 3, and 4 showed statistically significant results. Model 2 showed that job performance of regular employees was higher than that of irregular workers, although the explanatory power was not high. In Model 3, job efficacy was found to have a statistically significant effect $\left(\Delta \mathrm{R}^{2}=.469 / \mathrm{p}>.001\right)$. The influence of organizational support in Model 4 was statistically significant $\left(\triangle \mathrm{R}^{2}=.523 / \mathrm{p}>.001\right)$. In addition, it was confirmed that not only job efficacy but also organizational support were important factors affecting social workers' job performance. The results of this study indicate that the performance of social welfare organization depends not only on individual competence but also on the mutual interaction between individual and organization. Finally, this study suggests that systematic organizational support is necessary in order to improve the organizational performance of social welfare organization.
\end{abstract}

Keywords: Job Efficacy, Job Performance, Perceived Organizational Support, Social Worker, Supervision

\section{Introduction}

The fact that most work done by social welfare organizations depends heavily on social workers has led to widespread recognition that the quality of social worker performance relates directly to the quality of service clients receive[1]. Korea's social welfare system is largely divided between the private and public sectors, and most social welfare workers in the private sector work for social welfare NGOs.

This means that organizational support should take place at the organization level and

Received(July 13, 2018), Review Result(1st: July 26, 2018, 2nd: August 23, 2018), Accepted(September 10, 2018)

1) (Associate Professor) 31020 Dept. Social Welfare, Namseoul Univ. 91 Daehakro, Seounghwaneup Seobukgu Cheonan-si, Chungcheongnam-Do, Korea

email: sychoi@nsu.ac.kr 
address issues beyond individual competence and the quality of social worker performance[2]. Because the skills needed in social welfare organizations have so many indeterminate characteristics, non-skilled social workers must be systematically supervised to ensure that clients receive high quality service and to improve social worker job performance[3].

In contrast to the United States where social work is rarely practiced privately, human resource management, organizational support, and periodic supervision of social workers are important factors affecting the quality of social welfare services and the job performance of social workers in Korea. Social workers' job performance is important because it is linked not only to the quality of service clients receive but also to the ethical responsibility of service provision[4]. However, most discussions of social worker job performance have, to this point, remained largely conceptual. This is because clearly defining social worker job performance is difficult and no universally valid measurement tool for measuring job performance currently exists. For this reason, social welfare organization performance is mainly discussed in terms of program or case results, rather than in terms of objective job performance measures.

Although defining and measuring the performance of social workers remains difficult, the job performance of social workers is inseparable from the quality of service clients receive. Therefore, more empirical studies of social worker job performance are urgently needed. In addition, even though social worker job performance depends heavily on the individual expertise of social workers (e.g., their knowledge and skills), organizational support (e.g., human resource management systems and organizational supervision) also affect social worker job performance. Therefore, researchers must consider various management strategies to improve the job performance of social workers who are members of social welfare organizations.

This study aims to identify the level of organizational support social workers perceive and to investigate the effect of organizational support on individual social workers' job performance. This study is significant in that it deals with social worker job performance comprehensively not limited to specific programs or cases. The fact that it empirically examines the organizational factors that affect organizational performance, deriving implications for effective organizational management in the context of increasing demands social welfare organization responsibility also makes it significant.

\section{Theoretical Background}

Based on social learning theory, efficacy refers to one's confidence in one's ability to successfully perform tasks. Numerous studies in diverse fields have demonstrated the positive 
effects of efficacy on job-related problem solving and job performance[5]. Researchers have, for example, shown the positive the effects of efficacy on student achievement and organizational performance. This is also true of social worker job efficacy. Indeed, efficacy can be applied to a variety of social welfare organizations.

The factors that affect job performance are multifaceted. While individual characteristics tend to play a large role in job performance, organizational characteristics including leadership, organizational management, supervision of supervisors, and organizational work environment can also affect job performance[6]. In a broader sense, the environment surrounding any given organization will also impact performance. Because factors that affect job performance cannot be reduced to a single variable, job performance should be examined in terms of the interactions between organizations and individuals. First, personal ability should be gauged based on individual knowledge and skills. Because the ability to perform tasks varies from organization to organization and task to task, measuring work-related efficacy as a concept that can be generally applied and regarded as a precursor of job performance is preferable[7]. Brewer and Coleman[6] also highlight the individual and organizational factors that influence organizational performance. Personal factors include personal characteristics such as individual work capacity and job ability. Top priority organizational factors include leadership and supervision. In fact, leadership is the most frequent contributor to organizational performance in all types of organizations, where leadership promotes higher levels of organizational performance[8].

Researchers have conducted past studies of social worker efficacy by setting efficacy either as a preceding variable or a resultant variable. Such studies have identified the supervision and leadership as factors that potentially affect professional efficacy, while confirming the effect of efficacy on work effectiveness. However, although studies in the field of organization management have confirmed the effects of individual job efficacy on job performance, studies in the field of social work have not examined the effects of job efficacy on job performance[9][10].

The important factors in discussions of job performance include organizational management and organizational support. Because social welfare organizations are specialized organizations that mostly operate according to government guidelines, they are financially weaker than private companies. Therefore, they have relatively weak employee compensation, benefits, and human resource management support. Studies conducted on social welfare organizations have therefore tended to serve as status reports that highlight the financial struggles of organizations, and seek to improve job satisfaction and minimize the turnover. Research on the organizational support for job performance lacks the foundation for active discussion. 
Organizational support is a broad concept that involves emotional and material support, as well as support for teams and individual members. Organizational support includes support for organizational members and, as a consequence, the interconnection of individual and organization through organizational commitment and positive outcomes[11]. In other words, organizational support for members in an organization is an interchangeable concept that one wants to achieve through support. This is because organizational support does not simply concern the satisfaction of organizational members; rather, it is an antecedent of the job commitment and positive attitudes and behaviors of individual members of organizations[12].

In summary, the factors that influence job performance can be divided into organization-level variables and individual-level variables, because organizations and individuals are interactively related. In other words, even if an organization manages performance through systematic organizational support, an individual's inability or lack of competence may be negative for organizational performance. Nevertheless, paying more attention to organizational variables to promote job performance is necessary because organizational support can affect individual motivation and job efficacy. Therefore, when discussing the factors that affect job performance, considering the interactional dimensions of the two categories rather than the organization- or individual-level variables in isolation may be more appropriate. The organization-level factors that influence job performance include organizational structure, human resource systems, and leadership, while the individual factors include job motivation and individual job efficacy. Among these, the majority of studies regard leadership and supervision as the variables that most strongly influence job performance.

\section{Research Method}

\subsection{Research Hypotheses}

The research problems and hypotheses of this study are as follows.

First, what is the level of job efficacy and organizational support perceived by social workers?

Second, do job efficacy and organizational support affect social worker's job performance?

Third, does organizational support have a significant effect on social worker's job performance when the influence of individual variable (job efficacy) is controlled? 


\subsection{Data Collection}

This study conducted a survey intended for social workers who participated in social welfare retraining education program from June to July 2013. Before the survey, the researcher explained the purpose of the survey and encouraged voluntary participation in the survey. 211 respondents answered the questionnaire and 204 were used for statistical analysis, except for seven cases that could result in errors because of a consistent pattern of responses.

\subsection{Measures}

Organizational support was measured by a measure that was used in the previous domestic research. The measure consisted of five items: (1)fair treatment by the organization, (2)efforts to meet employee opinions, (3)consideration of the interests of members, (4)openness of information, (5)creation of participatory environment. Efficacy means self-confidence that one can perform tasks effectively[13].

Efficacy was measured by a measure that was developed by Jones, and used in Choi's study [14]. The measure was composed of eight items including work-oriented self-confidence, competence, job ability, job superiority, and challenging mind[14]. The higher the score, the higher the efficacy was. In previous study, reliability was reported as .889 . The content of the items are as follows: (1)whether the work is in the scope of one's ability; (2)whether it is difficult to perform the work; (3)whether one is capable of performing the work; (4)whether one has the knowledge and practical experience necessary for the work; (5)whether one has more knowledge and ability than one's colleague; (6)whether one have the confidence to perform the work successfully; (7)whether the work is challenging; and (8)whether one can do more beyond current work?

Previous domestic research demonstrated the reliability of this study's job performance measures, which included the following nine items: (1)rapid execution of one's work, (2)accuracy and trustworthiness of work, (3)understanding and effectively judging superior's direction, (4)negotiation and coordination skills, (5)reporting and expression, (6)observance of workplace rules, (7)cooperation with colleagues, (8)positive evaluations of job performance, and (9)good work practices[15]. 


\subsection{Statistical Analysis Method}

Statistical analysis was performed using SPSS 18.0. Descriptive statistics examined the general characteristics of the respondents and the average of the major variables. The hierarchical regression analysis was used to determine the effects of preceding variables on job performance.

\section{Results of Analysis}

\subsection{General Characteristics of Respondents and Descriptive Statistics}

[Table 1] shows the general characteristics of the respondents: 79 men (39.3\%), and 122 women $(60.7 \%) .134(66.7 \%)$ were university graduates, followed by graduate students (41, 20.4\%), professional college graduates $(25,12.4 \%)$, and doctoral students $(1,0.5 \%)$, respectively.

As for the position, the highest percentage was low-rank social worker with 99 (48.5\%), followed by frontline manager, middle manager, and high manager. Employment types were 174 regular employees $(85.3 \%)$ and some irregular workers $(29,14.3 \%)$. The average age was 33 years, and the total average work experience in social welfare organizations was 69.6 months.

[Table 1] General Characteristics of Respondents

\begin{tabular}{|l|l|l|}
\hline \multicolumn{2}{|c|}{ General Characteristics of Respondents } & \multicolumn{1}{|c|}{ Frequency (\%) } \\
\hline $\begin{array}{l}\text { Gender } \\
\mathrm{n}=201\end{array}$ & Male & $79(39.3 \%)$ \\
& Female & $122(60.7 \%)$ \\
Education & College Graduates & $25(12.4 \%)$ \\
$\mathrm{n}=201$ & University Graduates & $134(66.7 \%)$ \\
& Graduate Students & $41(20.4 \%)$ \\
& Doctoral Students & $1(0.5 \%)$ \\
\hline Employment Type & Regular Employee & $174(85.3)$ \\
$\mathrm{n}=203$ & Irregular Worker & $29(14.3)$ \\
\hline \multirow{3}{*}{ Position } & High Manager & $2(12.7 \%)$ \\
$\mathrm{n}=199$ & Middle Manager & $40(19.6 \%)$ \\
& Frontline Manager & $48(23.5 \%)$ \\
\hline Age & Social worker & $99(48.5 \%)$ \\
\hline Work Experience & Average & 33 year(SD7.3) \\
\hline
\end{tabular}

The average value of the major variables is shown in [Table 2]. The average of organizational support was 3.32, self-efficacy was 3.52, and job performance was 3.76, higher than other variables. The correlations among variables are shown in [Table 3]. 
[Table 2] Descriptive Statistics of Variables

\begin{tabular}{|l|l|l|l|l|l|l|l|l|l|}
\hline & $\mathrm{N}$ & $\mathrm{Min}$ & Max & Average & $\mathrm{SD}$ & \multicolumn{2}{|c|}{ Skewness } & \multicolumn{2}{|c|}{ Kurtosis } \\
\hline Organizational Support & 202 & 1.00 & 5.00 & 3.32 & .79 & -.233 & .171 & .093 & .341 \\
\hline Self-Efficacy & 203 & 1.57 & 5.00 & 3.52 & .64 & -.480 & .171 & .406 & .340 \\
\hline Job Performance & 201 & 2.44 & 5.00 & 3.76 & .48 & -.227 & .172 & .276 & .341 \\
\hline
\end{tabular}

[Table 3] Correlations among Variables

\begin{tabular}{l|l|l|l}
\hline & Organizational Support & Self-Efficacy & Job Performance \\
\hline Organizational Support & - & & \\
\hline Self-Efficacy & $.249^{* * *}$ & - & \\
\hline Job Performance & $.392^{* * *}$ & $.685^{* * *}$ & -- \\
\hline$* * * p<.001$ & \multicolumn{2}{|l}{}
\end{tabular}

\subsection{Results of Hierarchical Regression Analysis}

This study conducted a hierarchical regression analysis to confirm the effect of preceding variables on job performance. Multicolinearity has been found acceptable through tolerances and VIF. This study used hierarchical regression analysis to control the effects of gender, employment type, and job efficacy and to examine the effect of organizational support on job performance.

[Table 4] shows the results of statistical analysis of specified Models, which added one of different variables. Gender variable was added to Model 1, employment type to Model 2, job efficacy to Model 3, and organizational support to Model 4. Model 1 did not show statistically significant results in identifying gender effects. Model 2, 3, and 4 showed statistically significant results.

In Model 2, the employment type was found to be statistically significant. Job performance of regular employees was higher than that of irregular workers, although the explanatory power was not high $\left(\Delta \mathrm{R}^{2}=.024, \mathrm{p}>.05\right)$. In Model 3 that was designed to measure the impact of job efficacy on job performance, job efficacy was found to have a statistically significant effect on job performance $\left(\triangle \mathrm{R}^{2}=.469, \mathrm{p}>.001\right)$.

Model 4 confirmed statistically significant impact of organizational support on job performance $\left(\Delta \mathrm{R}^{2}=.523, \mathrm{p}>.001\right)$. 
[Table 4] Results of Hierarchical Regression Analysis

\begin{tabular}{|c|c|c|c|c|c|c|c|c|}
\hline & \multicolumn{2}{|c|}{ Model 1} & \multicolumn{2}{|c|}{ Model 2} & \multicolumn{2}{|c|}{ Model 3} & \multicolumn{2}{|c|}{ Model 4} \\
\hline & $\beta$ & $t$ & $\beta$ & $\mathrm{t}$ & $\beta$ & $\mathrm{t}$ & $\beta$ & $\mathrm{t}$ \\
\hline Gender $(0=$ Female $/ 1=$ Male $)$ & -.097 & -1.359 & -1.02 & -1.438 & -.083 & -1.592 & -.089 & -1.780 \\
\hline $\begin{array}{l}\text { Employment Type } \\
(0=\text { Irregular } / 1=\text { Regular })\end{array}$ & & & .157 & $2.217^{*}$ & .080 & 1.532 & .073 & 1.444 \\
\hline Job Efficacy & & & & & .672 & $12.767^{* * *}$ & .614 & $11.80^{* * *}$ \\
\hline Organizational Support & & & & & & & .221 & $4.259^{* * *}$ \\
\hline Constant & \multicolumn{2}{|c|}{3.807} & \multicolumn{2}{|l|}{3.630} & \multicolumn{2}{|l|}{1.952} & \multicolumn{2}{|l|}{1.671} \\
\hline $\mathrm{R}^{2}$ (Adjusted $\mathrm{R}^{2}$ ) & \multicolumn{2}{|c|}{$.009(.004)$} & \multicolumn{2}{|c|}{$.034(.024)$} & \multicolumn{2}{|c|}{$.478(.469)$} & \multicolumn{2}{|c|}{$.523(.513)$} \\
\hline F(F Sig.) & \multicolumn{2}{|c|}{$1.847(.176)$} & \multicolumn{2}{|c|}{$3.399(.035)$} & \multicolumn{2}{|c|}{$58.502(.000)$} & \multicolumn{2}{|c|}{$52.327(.000)$} \\
\hline
\end{tabular}

\section{Conclusion}

Most of the studies on the work of social workers have focused on the positive attitude and effective behavior of social workers such as organizational commitment, job satisfaction, and organizational citizenship behavior. Scant attention, however, has been paid to the empirical analysis of social workers' job performance. Therefore, the significance of this study is that it is an empirical study on the job performance of social workers.

Even though this study is limited by the lack of objective measure of job performance, it lays the foundation for future research on social workers' job performance.

The major findings of this study are as follows. First, social workers tend to evaluate their job performance positively. This study shows that the average of job performance is somewhat higher than job efficacy or organizational support. Next, although the explanatory power of job performance is not large, regular employees recognize that their job performance is higher than non-regular workers' job performance.

In addition, the study confirms that job efficacy is a key variable explaining job performance because job efficacy is directly connected to problem solving ability. Organizational support is another statistically significant variable explaining social workers' job performance.

Based on the results of this study, the following suggestions can be made as follows. First, organizational support should be systematized to improve social worker's job efficacy. Considering that educational supervision affect social welfare efficacy[16], it is necessary to strengthen the educational function of supervision to maximize social worker's knowledge and skills and to make efforts to promote their job efficacy. 
In other words, it is necessary to strengthen systematic supervision to enhance social worker's work capacity and improve their job efficacy. This is part of the ethical responsibility of both social workers and social welfare organizations, because social workers' competence plays an important role in the quality of service provided for clients.

Second, organizational support should include fair treatment by the organization, efforts to meet employee opinions, consideration of the interests of members, openness of information, and creation of participatory environment. Due to the poor work environment of many social welfare organizations, organizational support is not enough to support social worker's individual growth and personal interests.

In the case of social welfare organizations, it is necessary to recognize that various non-material supports can lead to individual growth as well as to organizational growth, since material compensation is limited in social welfare organizations.

Third, it is necessary to consider the appropriate work environment of individual and organization. Job performance cannot be explained only at individual level or organization level. It should be considered in terms of the interaction of individual competence and organizational support. Therefore, an organization's individualized support strategy needs to be linked to maximize individual competence.

This study confirms the effects of individual's job efficacy and organizational support on job performance. Future research needs to examine the mutual influence of individual's job efficacy and organizational support, and to expand the discussion of social worker' job performance that plays a pivotal role in the service quality of social welfare organizations.

\section{References}

[1] J. A. Lewis, M. D. Lewis, T. Packard, and F. Jr. Soufflée, Management of Human Service Programs, Wadsworth/Thomson Learning, Belmont, CA, (2001)

[2] S. Y. Choi, The Effects of Superior Supervision on Social Workers' Professional Efficacy, International Journal of Social Welfare Promotion and Management, (2016), Vol.3, pp.193-198.

[3] Y. Hasenfeld, Human Service as Complex Organization, SAGE Publication, CA, (1992)

[4] S. Y. Choi, Does Social Work Supervision Affect Social Workers' Professional Efficacy?-Focusing on the Effects of Three Functions of Supervision, Informations-An International Interdisciplinary Journal, (2017), Vol.9(B), pp.6867-6874.

[5] A. Bandura, Perceived Self-Efficacy in Cognitive Development and Functioning, Educational Psychologist, (1993), Vol.28, No.2, pp.117-148. 
[6] G. A. Brewer and S. Coleman, Why Elephants Gallop: Assessing and Predicting Organizational Performance in Federal Agencies, Journal of Public Administration Research and Theory, (2000), Vol.10, No.4, pp.685-711.

[7] S. Y. Choi, Study on the Social Work Self-Efficacy of Social Work Students, Korean Journal of Social Welfare Education, (2010), Vol.12, pp.73-96.

[8] G. A. Brewer and S. Coleman, Why Elephants Gallop: Assessing and Predicting Organizational Performance in Federal Agencies, Journal of Public Administration Research and Theory, (2000), Vol.10, No.4, pp.685-711.

[9] E. R. Greenglass, R. J. Burke and K. A. Moore, Reactions to Increased Workload: Effects on Professional Efficacy of Nurses, Applied Psychology: An International Review, (2003), Vol.52, No.4, pp.580-597.

[10] R. Wood and A. Bandura, Social Cognitive Theory of Organizational Management, Academy of Management Review, (1989), Vol.14, pp.361-384.

[11] M. L. Wang, Does Organizational Support Promote Citizenship in Service Settings?-The Moderating Role of Service Climate, The Journal of Social Psychology, (2009), Vol.149, No.6, pp.648 - 676.

[12] R. Eisenberger, J. Cummings, S. Armeli and P. Lynch, Perceived Organizational Support, Discretionary Treatment, and Job Satisfaction, Journal of Applied Psychology, (1997), Vol.82, No.5, pp.812-820.

[13] Y. W. Lee, A Study on the Determinants of Service Orientation: Based on Perceived Organizational Support, Loyalty, and Self-Regulation in Sport administration, Master Dissertation, Hanyang University, (2011)

[14] I. W. Choi, The Impact of Middle Managers Coaching on Subordinates' Job Attitudes in Public Institutions through Mediating Effect of Organizational Trust and Self-Efficacy, Doctoral Dissertation, Soongsil University, (2013)

[15] H. Y. Lee, The Effects of Airline Flight Attendant's Perceived Organizational Justice on Job Performance: Focusing the Mediating Effects of Ethical Climate, Master Dissertation, Sejong University Graduate School, (2009)

[16] S. Y. Choi, Does Social Work Supervision Affect Social Workers' Professional Efficacy? Focusing on the Effects of Three Functions of Supervision, Information-An International Interdisciplinary Journal, (2017), Vol.20, No.9(B), pp.6867-6874. 